\title{
Associação fitoterápica no tratamento de feridas cutâneas induzidas em equinos
}

\author{
[Herbal combination in the treatment of equine skin induced wounds] \\ G. Ribeiro, M.A.G. Silva, C.B. Martins, V.P. Borges, J.C. Lacerda Neto
}

Faculdade de Ciências Agrárias e Veterinárias - Universidade Estadual Paulista (Unesp) - Jaboticabal, SP

\section{RESUMO}

Estudou-se a eficácia do uso tópico de um produto comercial constituído por uma associação fitoterápica como promotor da cicatrização de feridas induzidas em equinos. Uma lesão cutânea em forma de quadrado, com $5 \mathrm{~cm}$ de lado, foi produzida cirurgicamente em ambos os lados da região glútea de oito cavalos adultos. Aleatoriamente um dos lados foi escolhido como tratado, permanecendo o contralateral como controle. As lesões do lado controle foram lavadas com água e detergente neutro e, no lado tratado, foi realizado o mesmo procedimento, seguido de aplicação tópica da associação fitoterápica. As evoluções macroscópica e microscópica do processo cicatricial foram avaliadas, e a área de cada ferida determinada no decorrer do período experimental. Foram encontradas diferenças significativas entre os lados em relação aos valores de área das feridas. Na última avaliação, o lado controle apresentou valor médio de área de $0,70 \mathrm{~cm}^{2}$, e o lado tratado de $1,23 \mathrm{~cm}^{2}$. A contração cicatricial observada em 77 dias de evolução cicatricial foi de $97,57 \%$ para o lado controle e de $95,59 \%$ para o lado tratado.

Palavras-chave: cicatrização, feridas, equinos, fitoterapia, pele

\begin{abstract}
The efficiency of the topical use of a commercial product constituted by a herbal combination on the healing evolution of equine induced wounds was studied. A skin lesion in the shape of a square with $5 \mathrm{~cm}$ sides was surgically produced on both sides of the buttocks of eight adult horses. One side was considered control and another one treated. Both control and treated sides were rinsed with water and neutral soap. Additionally, the wound on the treated side received the topical treatment with the herbal combination. Macroscopic and microscopic healing evolution of the wounds was evaluated and their areas were determined during the experimental period. There was statistical difference between wound areas. At the last evaluation, the average area of the control side was $0.70 \mathrm{~cm}^{2}$ and of the treated side was $1.23 \mathrm{~cm}^{2}$. The contraction of scar observed at 77 days was $97.57 \%$ for the control side and $95.59 \%$ for the treated side.
\end{abstract}

Keywords: healing, wound, horses, herbal therapy, skin

\section{INTRODUÇÃO}

Ao longo das últimas décadas, pesquisadores de vários centros de estudo vêm investigando a utilização de diferentes materiais no intuito de suprir as deficiências do tratamento convencional das feridas cutâneas. Com a evolução da medicina, surgiram substâncias que tinham crédito de ajudar no processo de cicatrização. Algumas permaneceram com esse crédito, outras não (Matera, 2002).
Atualmente, observa-se uma busca crescente pela utilização de produtos naturais para o tratamento de várias enfermidades, concomitantemente ao desenvolvimento de novas formas farmacêuticas e técnicas para o controle de qualidade. Esses fatos têm impulsionado a pesquisa de novas substâncias ativas com base no conhecimento popular (Bürger et al., 2003).

O presente trabalho visou analisar a eficácia como promotor de cicatrização na espécie equina

Recebido em 24 de maio de 2012

Aceito em 16 de abril de 2013

E-mail: gesiane_r@yahoo.com.br 
de um produto comercial (Fitofix, Fitovet, Brasil) composto por uma associação de plantas medicinais e própolis que, conforme indicação do fabricante, promove rápida cicatrização e regeneração dos tecidos em ferimentos de qualquer natureza.

\section{MATERIAL E MÉTODOS}

A realização deste trabalho foi aprovada pela Comissão de Ética no Uso de Animais (Ceua) da Faculdade de Ciências Agrárias e Veterinárias da Universidade Estadual Paulista (Unesp), Campus de Jaboticabal/SP, por meio do Protocolo $\mathrm{n}^{\circ}$ 020497-11. Para minimizar o número de animais envolvidos no experimento e para anular variações individuais, utilizou-se um único grupo de cavalos, que tiveram um lado considerado controle e outro tratado.

Foram utilizados oito equinos adultos, machos ou fêmeas, sem raça definida. Os animais foram mantidos em tronco de contenção e prémedicados com acepromazina (Acepran 1\%, Univet, Brasil), na dose de $0,05 \mathrm{mg} / \mathrm{kg}$, por via endovenosa. Após tricotomia e antissepsia de ambos os lados da região da garupa, realizou-se anestesia local infiltrativa com solução de lidocaína a $2 \%$ sem vasoconstritor (Xylestesin 2\%, Cristália, Brasil). Uma lesão cutânea em forma de quadrado foi produzida em cada lado da região glútea, utilizando-se um molde para a obtenção de lesões uniformes, com $5 \mathrm{~cm}$ de lado. Após a incisão com bisturi, a pele e o tecido subcutâneo foram removidos por dissecção utilizando-se tesoura romba e pinça anatômica com dente de rato.

Aleatoriamente, um dos lados foi escolhido como tratado, permanecendo o contralateral como controle. O tratamento realizado nas feridas de lado controle foi apenas a lavagem diária com água e detergente neutro e secagem com gaze esterilizada. Após esse procedimento, somente as feridas tratadas receberam a aplicação tópica de Fitofix ${ }^{\circledR}$. O referido produto possui apresentação em forma de spray e cada $100 \mathrm{~mL}$ contém: $20 \mathrm{~mL}$ de tintura de Calendula officinalis L, $20 \mathrm{~mL}$ de tintura de Stryphnodendron barbatiman, $10 \mathrm{~mL}$ de tintura de Symphytum officinalis L, $10 \mathrm{~mL}$ de tintura de Aloe vera $\mathrm{L}, 5 \mathrm{~mL}$ de tintura de Matricaria chamomilla $\mathrm{L}, 10 \mathrm{~mL}$ de Echinacea angustifolia DC, $15 \mathrm{~mL}$ de tintura de própolis, $10 \mathrm{~mL}$ de excipiente. $\mathrm{O}$ tratamento foi realizado seguindose as instruções contidas na embalageceirom do produto, em que se recomenda, no mínimo, uma aplicação diária. Durante os primeiros 14 dias, os curativos foram realizados a cada 12 horas, e, posteriormente, uma vez ao dia, até 77 dias de evolução cicatricial.

Foram realizadas avaliações das feridas cutâneas nos primeiro, terceiro, sétimo, $14^{\mathrm{o}}, 21^{\circ}, 28^{\mathrm{O}}, 35^{\circ}$, $42^{\circ}, 49^{\circ}, 56^{\circ}, 63^{\circ}, 70^{\circ}$ e $77^{\circ}$ dias. Os parâmetros macroscópicos relacionados à evolução do processo cicatricial observados foram: sensibilidade dolorosa à palpação digital ao redor da ferida, presença de tecido de granulação, secreções, crostas, hemorragia e edema. Esses parâmetros foram estimados em escala de 0 a 3 , sendo que 0 indicava ausência dos parâmetros avaliados, 1 ocorrência em até $30 \%$ da lesão, 2 ocorrência em $30 \%$ a $60 \%, 3$ ocorrência em $60 \%$ a $100 \%$ da lesão.

A colheita do material destinado à análise histológica foi realizada imediatamente após a cirurgia e nos terceiro, sétimo, $14^{\circ}, 21^{\circ}, 28^{\circ}$ e $63^{\circ}$ dias de pós-operatório. Foram colhidas amostras dos lados controle e tratado de apenas um animal em cada tempo, buscando-se evitar que traumatismos consecutivos reagudizassem $\mathrm{o}$ processo inflamatório e, com isso, interferissem no desenvolvimento do processo cicatricial.

O material obtido nas biópsias foi colhido das bordas das lesões e, posteriormente, fixado em formaldeído tamponado em solução aquosa a $10 \%$. Esse material foi reduzido a pequenos fragmentos, os quais foram submetidos às técnicas rotineiras de inclusão em parafina, cortados em micrótomo manual e corados com hematoxilina e eosina (HE) e também pelo tricrômio de Masson (TM). Os parâmetros avaliados microscopicamente foram: a integridade do epitélio, a organização do tecido conjuntivo, a presença de hemorragia, fibroplasia, hiperplasia epitelial, hiperqueratose, neovasos e os tipos celulares presentes.

Nas mesmas ocasiões em que as lesões foram avaliadas, seus contornos foram delineados com o uso de plástico transparente e caneta marcadora para retroprojetor, sendo esses esquemas, posteriormente, submetidos à análise por planimetria, utilizando-se um planímetro polar de compensação (modelo Aott Keupten, Alemanha) 
e obtendo-se a área de cada ferida no decorrer da evolução cicatricial. Com esses valores foi possível calcular a porcentagem de contração das feridas em 77 dias de evolução cicatricial, por meio da fórmula: contração = área inicial - área final/área inicial (Matera, 2002). Os valores das áreas das feridas, bem como os valores de contração, foram submetidos à análise pelo teste t pareado, com nível de significância de 5\%. Os parâmetros clínicos mensurados por escores foram analisados pelo teste não paramétrico Wilcoxon Signed Rank Test, que verifica diferenças entre pares ordenados (Vieira, 2004).

\section{RESULTADOS}

À inspeção das feridas, os sinais clínicos iniciais observados nos equinos deste estudo no primeiro e no terceiro dias foram: hiperemia do tecido superficial das lesões, nas quais se verificaram os maiores valores de sensibilidade, hemorragia, secreção e edema ao redor da área traumatizada. D'utra Vaz (1995) observou características clínicas semelhantes para lesões cutâneas em equinos avaliadas nos primeiros dias após a indução, as quais foram associadas ao pico da fase inicial do processo inflamatório. As avaliações histológicas das lesões realizadas neste mesmo período estão de acordo com os achados clínicos observados, uma vez que tanto nas feridas controle quanto nas tratadas verificou-se a presença de infiltrado inflamatório severo, predominantemente neutrofílico, interposto por significativo número de células mononucleares (Fig. 1).

Outra característica observada nas primeiras 24 horas após o ato cirúrgico foi um pequeno aumento dos valores de área das lesões em ambos os grupos experimentais. De acordo com Madison e Gronwal (1992), o processo de contração das feridas ocorre em três fases: uma fase inicial, na qual as bordas da ferida apresentam retração centrífuga e a área da lesão aumenta; a seguir, um período de contração rápida em direção ao centro da lesão, e, finalmente, quando a ferida está praticamente cicatrizada, o processo torna-se mais lento, deixando a curva de cicatrização na forma de platô. $\mathrm{O}$ aumento da área das lesões registrado logo após o traumatismo se deve, segundo Barber (1990), à associação da perda da tensão ao edema da pele.

Verificou-se, no exame das lesões realizado no sétimo dia, ausência de hiperemia, de sensibilidade e de hemorragia, além de edema discreto; microscopicamente se notou ausência do infiltrado inflamatório presente nas avaliações anteriores. Tais achados caracterizam o final da fase inflamatória aguda descrita por Silver (1982). Também a partir do sétimo dia, iniciouse um período de grande contração, com considerável redução da área das lesões, caracterizando a fase de contração rápida que se estendeu até 28 dias. Em seguida, iniciou-se a fase de contração lenta.

Neste trabalho, não foi verificada a presença de tecido de granulação visível em nenhum momento das avaliações. No entanto, há evidências histológicas a partir de 14 dias que caracterizam a fase de granulação, como intensa fibroplasia e neovascularização (Fig. 2).

Segundo Engelen et al. (2004), alguns fatores são responsáveis por promover a hipergranulação tecidual, entre eles: a localização da lesão (as partes mais baixas dos membros são mais predispostas), a mobilidade da região, a perfusão tecidual prejudicada, infecções e traumas. Diante do exposto, é possível compreender por que a hipergranulação não foi observada nesta avaliação, uma vez que não estava presente nenhum dos fatores predisponentes.

Aos 28 dias, iniciou-se uma fase de contração mais lenta, em que as lesões do grupo controle passaram a apresentar valores de área cada vez menores em relação às lesões tratadas. Essa diferença já era visível macroscopicamente em alguns animais (Fig. 3), mas tornou a média do grupo estatisticamente significativa somente nas duas últimas avaliações, com 70 e 77 dias (Tab. 1). 


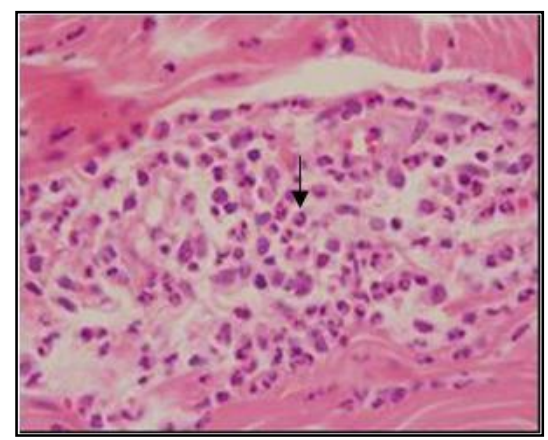

Figura 1. Fotomicrografia ilustrando lesão tratada com Fitofix ${ }^{\circledR}$, com três dias de evolução cicatricial. Região com infiltrado inflamatório predominantemente neutrofílico. Observar a presença de neutrófilo (seta) (HE, 100x).
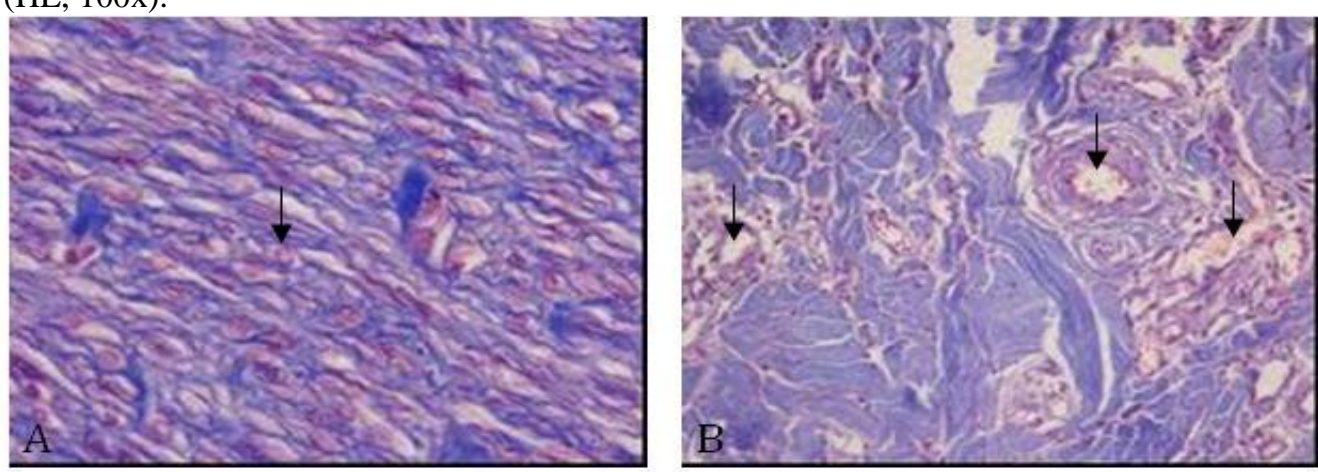

Figura 2. Fotomicrografias ilustrando em A: lesão tratada com Fitofix®, com 14 dias de evolução cicatricial. Região de intensa fibroplasia. Observar a presença de fibroblasto com núcleo ovoide (seta). (TM, 100x). B: lesão controle com 14 dias de evolução cicatricial. Região de neovascularização. Observar a presença de vasos (setas) (TM, 40x).
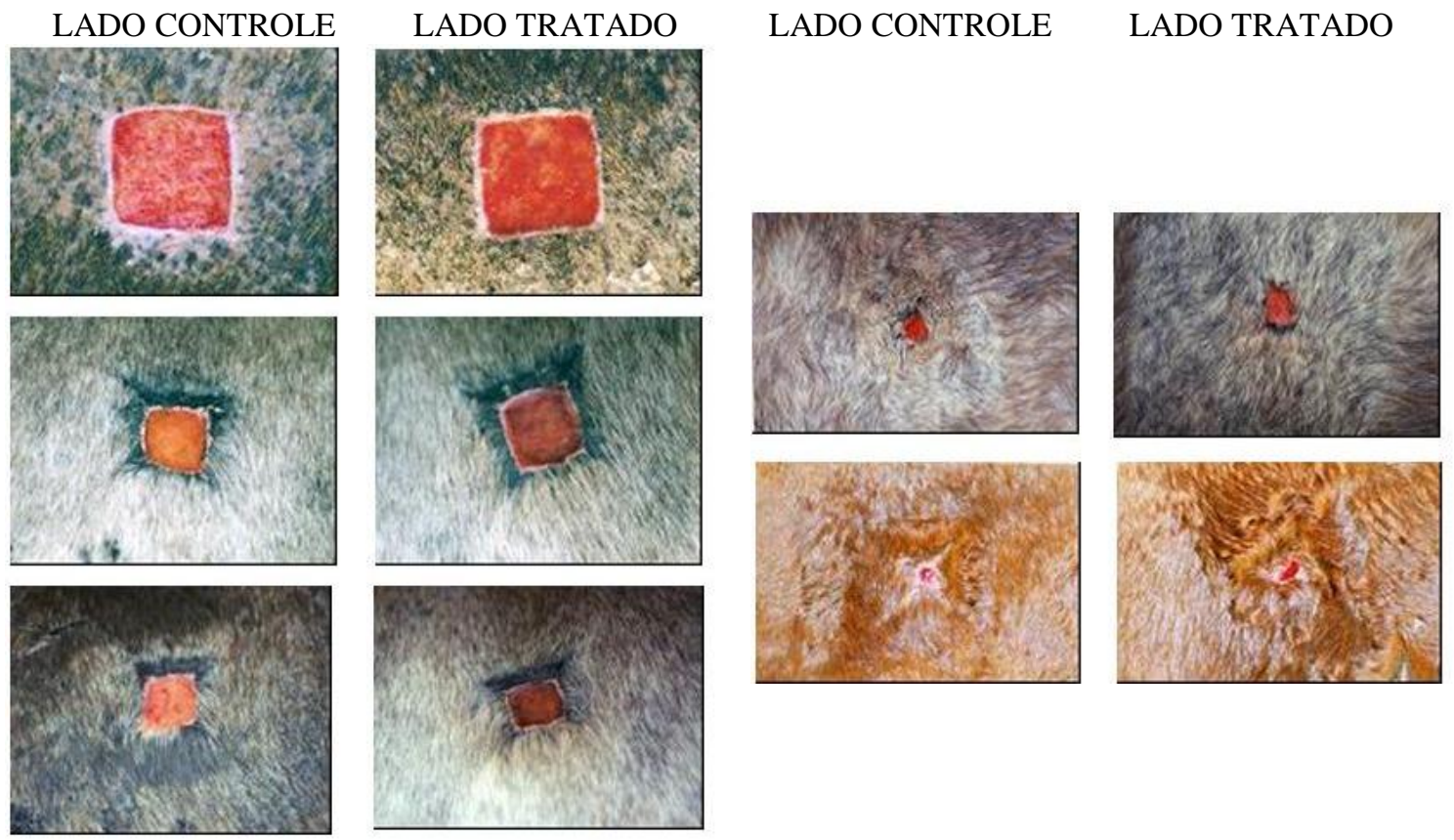

Figura 3. Ilustrações fotográficas nas quais se observam, à esquerda, as lesões do grupo controle e, à direita, as lesões tratadas com 14, 28, 42, 63 e 77 dias de evolução cicatricial. 
Tabela 1. Valores médios de área das feridas do grupo tratado e do grupo controle no decorrer do tempo e porcentagem de contração das feridas ao final do experimento

\begin{tabular}{ccc}
$\begin{array}{c}\text { Tempo } \\
(\text { dias })\end{array}$ & $\begin{array}{c}\text { Área }\left(\mathrm{cm}^{2}\right) \\
\text { Grupo } \\
\text { tratado }\end{array}$ & $\begin{array}{c}\text { Área }\left(\mathrm{cm}^{2}\right) \\
\text { Grupo controle }\end{array}$ \\
\hline 0 & 25,00 & 25,00 \\
1 & 28,74 & 30,07 \\
3 & 27,69 & 28,78 \\
7 & 22,65 & 23,45 \\
14 & 15,11 & 16,00 \\
21 & 10,01 & 10,83 \\
28 & 7,99 & 8,14 \\
35 & 5,74 & 5,72 \\
42 & 4,47 & 4,26 \\
49 & 3,69 & 3,42 \\
56 & 3,11 & 2,88 \\
63 & 2,59 & 2,04 \\
70 & $1,79 *$ & 1,17 \\
77 & $1,23 *$ & 0,70 \\
\hline$\%$ & $95,59 \% *$ & 97,57 \\
\hline
\end{tabular}

Contração

* indica diferença estatística entre os grupos $(\mathrm{p} \leq 0,05)$.

A diferença observada entre os valores de área das feridas tratadas e controle no final das observações resultou em diferença significativa entre os grupos nos valores de contração das feridas, significando que as lesões tratadas cicatrizaram mais lentamente que as lesões do grupo controle.

\section{DISCUSSÃO}

A literatura científica relata o uso de fitoterápicos com diversas indicações terapêuticas, sendo alguns deles de uso consagrado e pertencentes à farmacopeia brasileira (Martins et al., 2003). É bastante conhecido, por exemplo, o uso popular do barbatimão, produto fitoterápico extraído a quente em solução aquosa de Stryphnodendron barbatiman. O barbatimão contém em sua casca $20 \%$ de tanino, princípio ativo que lhe confere ação adstringente, o que explica seu uso como cicatrizante. Os taninos precipitam proteínas dos tecidos lesados, formando um revestimento protetor que favorece sua reparação, diminuindo a permeabilidade e a exsudação da ferida (Martins et al., 2003). Além disso, também tem sido relatado que o extrato aquoso do Stryphnodendron barbatiman possui propriedades anti-inflamatória, analgésica e protetora da mucosa gástrica (Bezerra et al., 2002; Rebecca et al., 2002).

A Calendula officinalis foi amplamente empregada na medicina popular europeia, sendo atualmente aprovada pela comissão científica alemã como antisséptica e cicatrizante. Possui em sua composição uma fração lipofílica, os triterpenoides, responsáveis pela ação anti-inflamatória, carotenoides, flavonoides, carboidratos, ácidos graxos e polissacarídeos, que lhe conferem ação epitelizante e imunoestimulante (Martins et al., 2003).

A Matricaria chamomila (camomila) também é uma planta originária da Europa que atualmente é conhecida em quase todos os continentes. Durante séculos ela vem sendo utilizada como planta medicinal, principalmente para o tratamento de afecções gastrointestinais. Também é usada por via oral para aliviar a ansiedade e a insônia, e topicamente para estimular a cicatrização de ferimentos (Macchioni et al., 2004).

O própolis é uma resina produzida por abelhas e tem sido empregado na ortopedia, endocrinologia, dermatologia, pneumatologia, gastroenterologia e odontologia. Foram identificados muitos elementos químicos no própolis, entre eles ferro e zinco, que são relevantes para a síntese de colágeno; também foi demonstrada a presença de aminoácidos, como arginina e prolina, importantes estimuladores da mitose celular e matéria-prima para síntese proteica (Magro-Filho et al., 1994).

A Aloe vera, conhecida popularmente como babosa, possui várias propriedades terapêuticas, incluindo cicatrização de ferimentos e injúrias térmicas, ação anti-inflamatória e imunomoduladora. Visando à utilização desses efeitos, a Aloe vera é atualmente empregada em inúmeros produtos comerciais, incluindo protetores solares, cosméticos e loções (Choi et al., 2001).

Apesar de tantos relatos na literatura sobre a utilização destas substâncias no tratamento de lesões cutâneas, as observações encontradas no presente trabalho não comprovaram o efeito promotor de cicatrização do produto fitoterápico 
utilizado sobre feridas cutâneas induzidas em equinos.

O resultado encontrado foi semelhante ao obtido por Bürger et al. (2003), que avaliaram a cicatrização em ratos de feridas tratadas ou não com pomada caseira à base de plantas medicinais e própolis. No estudo citado, a avaliação microbiológica e a redução da área das lesões foram semelhantes entre os grupos, porém a reepitelização foi mais avançada no grupo controle. Da mesma forma neste experimento, as lesões dos grupos tratado e controle evoluíram de maneira muito semelhante durante 28 dias, e somente a partir de então, as feridas controle passaram a cicatrizar mais rapidamente. Esse período coincidiu com o final da fase de contração rápida e, a partir daí, provavelmente, a fase de epitelização passou a ter papel mais decisivo na cicatrização das lesões. Na avaliação microscópica desse período, observaram-se hiperplasia epitelial e hiperqueratose.

Estes resultados estão de acordo com Contrera et al. (1985), os quais verificaram que o emprego de plantas de uso popular na cicatrização cutânea poderia diminuir a reepitelização. De acordo com a literatura, o própolis apresenta ação antimicrobiana, anestésica e estimulante da regeneração de tecidos (Bürger et al., 2003). Porém, Carvalho et al. (1991) não constataram a ação antimicrobiana do própolis presente em um creme associado ao confrei e ao mel. Rahal et al. (2003), ao avaliarem a utilização do própolis ou do mel no tratamento de feridas induzidas em ratos, também não verificaram diferenças significativas entre o efeito de cada tratamento. Magro-Filho e Carvalho (1990) concluíram que a aplicação tópica de solução hidroalcoólica de própolis não tem efeito na cicatrização de cavidades dentárias.

Além do própolis, muitas espécies de plantas de uso popular descritas como cicatrizante e estimulante da regeneração dos tecidos não demonstraram esses efeitos dentro da técnica desenvolvida e dos parâmetros utilizados. Schmidt e Greenspoon (1991), ao avaliarem a utilização de Aloe vera na cicatrização de ferimentos resultantes de cesarianas ou outras cirurgias ginecológicas em um estudo com mulheres, constataram que o uso do gel de Aloe vera promoveu atraso significante no tempo de cicatrização.
Segundo Bürger et al. (2003), é importante observar que a preparação de produtos fitoterápicos, que mistura várias espécies de plantas e própolis, pode apresentar ações antagônicas. Carvalho et al. (1991) sugerem que uma mistura de própolis ao confrei e mel poderia anular os efeitos antimicrobianos atribuídos ao própolis. Os referidos efeitos antagônicos seriam melhor observados se as plantas fossem estudadas individualmente, pois até em uma mesma espécie observa-se a presença de princípios ativos de ações contrárias, melhor observadas após estudos com extratos fracionados (Bürger et al., 2003).

\section{CONCLUSÃO}

Com base nos resultados obtidos, pode-se afirmar que a aplicação tópica do produto à base de plantas medicinais e própolis utilizado neste estudo não exerceu efeito sobre a cicatrização das feridas cutâneas induzidas em equinos durante as primeiras quatro semanas. Porém, a partir de então, as feridas do grupo controle passaram a cicatrizar mais rapidamente que as feridas tratadas, mostrando um possível efeito deletério do produto durante a fase de epitelização; esse efeito foi estatisticamente significativo a partir da $10^{\mathrm{a}}$ semana. Assim, conclui-se que, em feridas cutâneas induzidas na região da garupa de equinos, o produto promoveu significativo atraso na fase final da cicatrização.

\section{REFERÊNCIAS}

BARBER, S.M. Second intention wound healing in the horse: The effect of bandages and topical corticosteroids. In: ANNUAL CONVENTION OF THE AMERICAN ASSOCIATION EQUINE PRACTIONERS, 35., 1990. Ontario. Proceedings...Ontario: [s.n.] 1990. p.107-116.

BEZERRA, J.C.B.; SILVA, I.A.; FERREIRA, H.D. et al. Molluscicidal activity against Biomphalaria glabrata of Brazilian Cerrado medicinal plants. Fitoterapia, v.73, p.428-430, 2002.

BÜRGER, M.; GHEDINI, P.C.; DORIGONI, P.A. et al. Cicatrização de feridas cutâneas em ratos tratados com Pomada caseira à base de plantas medicinais. Rev. Bras. Plantas Med., v.5, p.91-97, 2003. 
CARVALHO, P.S.P; TAGLIAVINI, D.G.; TAGLIAVINI, R.L. Cicatrização cutânea após aplicação de creme de calêndula e da associação de confrei, própolis e mel em feridas infectadas Estudo clínico e histológico em ratos. Rev. Cienc. Biomed., v.12, p.39-50, 1991.

CHOI, S.W.; SON, B.W.; SON, Y.S. et al. The wound-healing effect of a glycoprotein fraction isolated from Aloe vera. Br. J. Dermatol., v.145, p.535-545, 2001.

CONTRERA, M.G.D.; LOPES, R.A.; POZETTI, G. et al. Ação da tintura-mãe de Lichnophora ericoides, Aristolochia esperanzae e Solidago microglossa em feridas cutâneas de rato. Rev. Esc. Farm. Odontol. Alfenas, v.8, p.13-17, 1985.

D'UTRA VAZ, B.B. Evolução cicatricial de feridas cutâneas induzidas experimentalmente na espécie equina (Equus caballus), tratadas ou não com película de celulose. 1995. Dissertação (Mestrado em Cirurgia Veterinária). Faculdades de Ciências Agrárias e Veterinárias, Universidade Estadual Paulista, Jaboticabal.

ENGELEN, M.; BESCHE, B.; LEFAY, M.P. et al. Effects of ketanserin on hypergranulation tissue formation, infection, and healing of equine lower limb wounds. Can. Vet. J., v.45, p.144149,2004

MACCHIONI, F.; PERRUCCI, S.; CECCHI, F. et al. Acaricidal activity of aqueous extracts of chamomile flowers, Matricaria chamomilla, against the mite Psoroptes cuniculi. Med. Vet. Entomol., v.18, p.205-207, 2004.

MADISON, J.B.; GRONWALL, R.R. Influence of wound contraction in horses. Am. J. Vet. Res., v.53, p.1575-1578, 1992.
MAGRO-FILHO, O.; CARVALHO, A.C.P. Application of propolis to dental sockets and skin wounds. J. Nihon Univ. Sch. Dent., v.32, p.4-10, 1990.

MAGRO-FILHO, O.; CARVALHO, A.C.P. Topical effect of propolis in the repair of sulcoplasties by the modified Kazanjian technique - Cytologycal and Clinical Evaluation. J. Nihon Univ. Sch. Dent., v.36, p.102-111, 1994.

MARTINS, P.S.; ALVES, A.L.G.; HUSSNI, C.A. et al. Comparação entre fitoterápicos de uso tópico na cicatrização de pele de equinos. $A V S$, v.8, p.1-7, 2003.

MATERA, J. Ensaio da eficácia e de exequibilidade de uso do creme ou gaze impregnada com Triticum vulgare em feridas cutâneas. Artigos Técnicos em Série da ScheringPlough Coopers, São Paulo, n. 8, 2002. p.1-7.

RAHAL, S.C.; BRACARENSE, A.P.F.R.L.; TANAKA, C.Y. et al. Utilização de própolis ou mel no tratamento de feridas limpas induzidas em ratos. $A V S$, v.8, p.61-67, 2003.

REBECCA, M.A.; ISHII-IWAMOTO, E.L.; GRESPAN, R. et al. Toxicological studies on Stryphnodendron adstringens. $J$. Ethnopharmacol., v.83, p.101-104, 2002.

SCHMIDT, J.M.; GREENSPOON, J.S. Aloe vera dermal wound gel is associated with a delay in wound healing. Obst. \& Gynecol., v.78, p.115$117,1991$.

SILVER, I.A. Basic physiology of wound healing in the horse. Equine Vet. J., v.14, p.7-15, 1982.

VIEIRA, S. Bioestatística - tópicos avançados. 2.ed. São Paulo: Campus, 2004. 232p. 